Journal of Urban and Regional Analysis, vol. XIII, 1, 2021, p. 93 - 111

https://doi.org/10.37043/JURA.2021.13.1.6

\title{
SPATIAL ANALYSIS OF CRIME OCCURRENCE IN VARIOUS REGIONS OF IRAN WITH AN EMPHASIS ON SAFETY
}

\author{
Sayed Ali HOSSEINI, Zohreh HADYANI, Hossein YAGHFOORI \\ University of Sistan and Baluchestan, Zahedan, Iran
}

\begin{abstract}
Safety is a basic issue in every social system and communities consider safety as one of their main priorities. One of the most important factors that put the safety of various communities at risk is the threats caused by crime occurrence. This paper is aimed to spatially analyze crime occurrence in various regions of Iran with an emphasis on safety. The research method is descriptive-analytical and a documentary and library data collection method is used. In this paper, the Similarity, COPRAS, mean rank method, and cluster analysis method are applied. The final results of the cluster analysis based on the mean rank method indicate a wide gap between the provinces of the country in terms of survey indicators, so that the final coefficient obtained for the provinces in the sixth cluster (the most unsafe group) is about 45 times of the final coefficient of the provinces in the first cluster (the safest group).
\end{abstract}

Key Words: spatial analysis, crime, safety, Iran

\section{Introduction}

Safety is a blessing because of which life exists and with the loss of which existence becomes dull; in its absence, life dies (Navidnia 2009). Safety practically covers all aspects of human life. Different aspects of safety, such as individual, national, social, aerial, road, food safety, etc., indicate the inclusiveness of safety in all aspects of individual life (Jahangiri and Mosavat 2013) and meeting many needs of the individual and society depends on safety, so that in the Maslow's hierarchy of needs, the sense of safety is put immediately after the satisfaction of basic needs. Therefore, safety is a basic issue in every social system and governments consider safety in the community as their first priority. One of the types of safety is social safety that is provided only with the recognition of behaviors that lead to increased or decreased safety in the "society". Social safety is a concept that is strongly tied with the fear of crime in social environments (Jafari et al. 2018). In two recent decades, the issue of urban safety and the necessity for reduced urban abnormalities have been the major concern for managers and planners, because safety is the basis and platform for economic, social, and environmental development and it is affected by these elements (Rahnemaei and Pourmousavi 2006). Increased safety in cities, in addition to apparent benefits such as strengthening the identity, vitality, efficiency, and beauty of space, has another advantage which is effective presence in the safe environment, where life, activity, investment, and business become more prosperous; as a result, we will observe further financial and economic growth. In contrast, unsafe spaces will repel people and investors (Hosseiniun 2007, Kalantari et al. 2010).

One of the most important threats to safety among the various classes of society is crime occurrence in that community. According to the available statistics and information, the trend of crimes is growing in most societies. This increasing trend from one location to another, depending on the type of crime, has differences from its own specific reasons and motifs. Crime causes numerous problems at community level. On the one hand, it causes insecurity, fear, panic, and disturbance of the citizens and, on the other hand, it endangers the health of cities and it forces the national judicial and law enforcement system to spend large funds on crime detection, prosecution, arrestment, and the custody of offenders, judicial proceedings, 
and punishment (Zangi Abadi and Rahimi Nader 2010, Nasiri et al. 2015). In total, due to the nature of crime and its consequences and effects, crimes have various types and classes, including theft, drugs, against persons, against property, social harms, traffic violations, etc. (Saraee and Hosseini 2015). From long time ago, identifying the causes of crime and efforts to eliminate or reduce their effects has been known as the most important prevention and reduction strategies for social anomalies. Crime prevention is an important issue, with which people have been involved for centuries. Crime prevention is a necessity to reform the lives of people worldwide. If it is possible to prevent someone from committing crimes and to reduce the opportunity of violations from various local-spatial and social aspects, the community would pass the pathway of improvement much faster and the crime rate in the society will be effectively declined.

Evaluating the evidence shows that due to the large amount of security problems and challenges that have been widespread in the large cities of Iran, many studies have been carried out on crime, centers of crime, and its effective factors that are mainly specific to urban areas, but there is a large study gap in the area of crime and the occurrence of crimes at the national level. Given the system governing and the national planning system, which is a topdown planning system, and most of the services and facilities that have been unfairly distributed in a few central and large provinces of the country, the general knowledge and the national overview of the status of crimes and the determination of the status of each province of the country in terms of crime occurrence seem to be essential. Besides, for assigning the necessary funds and credits regarding the establishment of safety and the fight against crime at provincial level, it is necessary to determine the status of each province among the other provinces of the country in the fair assignment of governmental credits and facilities. Given the above points, this paper seeks to perform a spatial analysis of crime occurrence in all regions of Iran, so in accordance with the frequency of crime occurrence in each of the provinces, the most safe and unsafe provinces are specified. Finally, with regard to the characteristics and features of each province, planning is done to provide safety.

One of the most important, complex, and new concepts in the modern world and in many political, social, and economic topics, is the concept of safety. Safety is considered as one of the basic needs and necessities of the individual and society, the lack or disturbance of which is followed by worried and dangerous consequences and reflections, so that civilized humans need safety or peace of mind to live among the others and to achieve high levels of growth, and with the growth of social crimes and deviations, unsafety and deviations at the community level cause the biggest concerns. Hence, the social safety is more essential than many other issues that might be considered important for the community (Saroukhani and Hashemnejad 2011). A stable and safe society must be described by rules and regulations or a set of measures against the threats that endanger the individual or social health (Cozens 2002). Hence, providing the safety of various groups of society has been one of the most important objectives of state and security institutions and, with the design and development of numerous programs, they attempt to detect the threats and to determine the ways of dealing with them and also to consider safety as the priority in their policies (Haji et al. 2011).

Safety is the sense of comfort and the assurance of lack of offences to the life, property, and other rights of humans. This exclusive value is one of the necessities of individual and social life (Kamyar 2000). The most important psychological need is safety that is considered as the most important goal of life and the essence of mental health (Fromm 1981). The concept of safety refers to the defense of one's self, family, friends, and property (Carmona et al. 2003). The point that should be noted is that different people, given the diversity of the environment, have different visions of safety and so that the sense of security is varied with respect to the economic system, the health system, and the individual insecurity experiences. They are more concerned with the fear of the sense of unsafety than the real and objective layers of insecurity and crime occurrence (Lindström 2008). In other words, the role and importance of the sense 
of safety among community members in the subjective dimension is next to the existence of safety in the objective dimension. Hence, some experts have noted that the sense of subjective safety is prior to the objective existence of safety (Saroukhani and Hashemnejad 2011). Therefore, promoting the sense of safety and, particularly, the subjective dimension of safety, is very important among the different groups of community (Rezaei Rad et al. 2007). Researchers believe that providing the necessary conditions to achieve a sense of safety is necessary for all citizens in all age and gender groups that should be considered by urban planners and officials (Tabrizi and Madanipour 2006). Generally, the sense of safety is a basic and important principle that individuals urgently need in order to demonstrate their abilities in the everyday life in urban spaces, place of residence, and workplace. Scholars have stated that the sense of safety is considerably important for the quality of life and public health of the residents of a community (Krevers and Milberg 2014). Hence, in order to improve and to increase the sense of safety among the individuals, it is necessary to provide certain facilities and necessities (Milberg et al. 2014). One of the most important measures to ensure security and the sense of safety for the citizens is crime reduction. Social anomalies and crimes that are committed by perpetrators and criminals in the urban environments are the main causes of unsafety in the living environments while preventing the safety of cities, and, as a result, disrupting the presence of people in public spaces and their social interactions. The people who are living in cities, whether they are living in their houses or they are in outdoors and public areas, are intentionally or unintentionally dealing with phenomena of crime occurrence and social anomalies, and the risk of crime occurrence is always threatening a citizen (Heshmati 2006). The lack of safety, the sense of danger, and the fear of crime reduce the use of public places and they increase the inefficiency of the urban environment. So, it can be said that the sense of safety and security is essential for the success of the urban design (Carmona et al. 2003).

It may be said that the first person to comment on the influence of the geographical environment on man was Hippocrates, the great physician of ancient Greece. He advised physicians to meditate more on climate, seasons, winds, weather, etc., and not to be unaware of the effect of these factors, and to use them to the best of their ability for the betterment of human beings (Kay Nia 1994). Crime hotspots have been in focus since the early nineteenth century, and at this time, due to the Industrial Revolution, a new phase of urbanism emerged, which led to an increase in the study of crime hotspots (Cozens 2008). But the main focus has been on the study of crime scene since the end of the twentieth century (Cook et al. 2013). In a series of surveys to determine how scattered is the delinquency of large American cities, Shaw and McKay (2014) found that delinquency usually peaks near downtown areas where rent is low and it decreases with distance from the city. Shaw and McKay (2014) work led to research into crime rates in Chicago and twenty other US cities over a period of more than 30 years. Studies based on scientific methods, principles and statistical methods about the geographical environment and crime were first conducted in the first half of the nineteenth century by Ketleh and Gary (Anselin 2000). Ketleh, the Belgian physicist and astronomer showed the correlation between the geographical environment and crime with the help of figures (Kay Nia 1994). Almost at the same time as Ketleh, Gary studied the geography of crime (Anselin 2000). In 1833 , he studied the relationship between poverty, population density, and education and the types of crime in five regions of France (Shakouei 1985). He also concluded in relation to heat and cold and the geographical environment that crimes against people occur more frequently in the south and in the summer, and property crime occur more frequently in the north and in the cold (Kay Nia 1994). Another study by Maller (1937), in New York, found that there were several areas in the city where young people were delinquent. Studies also found that there is a close relationship between juvenile delinquency and factors such as population density and economic status (Maller 1937, Ludwig et al. 2001). Also, Huntington (1945) researched the role of geographical factors in the occurrence of crimes. In 1929 and 1942, the concept of urban ecology, founded at the Chicago School by Park, Burgess, and McKenzie, was used by Shaw and McKay (2014). Based on the city's ecological features, the researchers found that the highest crime rates occur in neighborhoods with low-cost rental housing (Shaw and McKay 
2014). Crime follows the social physical pattern of the city. In other words, the existence of shortcomings in the organization of the police and the judiciary or in the devastated parts of the city provides favorable grounds for committing a crime (Glueck and Glueck 1950). In this regard, Wolfgang (1958) believed that almost all rape crimes take place between $8 \mathrm{pm}$ and 2 am after midnight. It is important to note that, in the rate of urban violence, there has always been a relationship between the stratum of the society and the type of work, so that the highest rate of violence among the working-class youth is much higher than among the second-class social youth (Ahmadi and Mohammad-Taghi 2004). On the other hand, most crimes and violence are committed by people who have been employed in the worthless jobs in the society. The study of crime rates in relation to the social structure is another part of the geographical study of crime. Some of the results of these studies show that neighborhoods with more single people also have higher crime rates. Also, in neighborhoods where the neighbors have known each other for many years, the crime rate is low. On the contrary, the lack of communication between the neighbors increases the crime rate (Hirshfield 2005).

Achu and Suja Rose (2016) focused on the examination and analysis of the phenomenon of crime and its spatial changes using GIS for the city of Thiruvananthapuram. The analytic results indicated the presence of critical points within this city in- Kerala, India, for crimes such as murder, robbery, kidnapping, and theft (Achu and Suja Rose 2016). Yar and Nasir (2016) focused on the examination and GIS spatial and temporal analyses of crimes in the city of Mardan, Pakistan. The results of the temporal analysis showed that almost $50 \%$ of the reports of crimes occurred in the summer and $35 \%$ of the reports were given in winter. The results of the spatial analysis also indicated 5 critical points for the occurrence of crimes in Pakistan (Newton 2015, Yar and Nasir 2016). The Temporal profiling of the MCC hot spots revealed that all four crime types were simultaneously present in time and place, near licensed premises, from Friday through Sunday, in the early hours of the morning, around the closing times of the premises. At other times, criminal damage and drugs hot spots were found to occur earlier in the evening, and disorder and violence at later time periods (Newton 2015). Zhong et al. (2011) focused on the spatial analysis of the crime model in Shanghai, using the police records and geographic information systems. The results demonstrated that the crime concentration was relatively high in some major points in the downtown, transport stations, as well as highly populated areas and gradually decreased from the center to the margin (Zhong et al. 2011).

In the present study, the emphasis is on the spatial distribution of crime in the provinces of Iran, but today the growth of crime in cities, especially metropolises in all countries of the world, is the most serious social issue. In particular, informal settlements and suburban areas, which often accommodate ethnic and racial immigrant groups, are the most affected, while these groups have a lower social and economic status than the main inhabitants of large cities (Ardian et al. 2014). Also, deprivation and the lack of facilities in the isolated settlements and suburban areas compared to other urban areas, the high unemployment rate, the problems of adaptation to the social environment, the lack of familiarity with the urban jobs, poverty and the cultural duality of the immigrants and people living in these areas, as well as the lack of proper support for these spaces, have provided the ground for committing crimes within these settlements and, consequently, mostly in urban areas (Méreiné-Berki et al. 2017, Crețan and O’Brien 2019, Málovics et al. 2019a, Málovics et al. 2019b, Vesalon and Crețan 2019, Crețan 2020).

Numerous studies have been conducted on the topic of crime and its spatial distribution in Iran (Rezaei et al. 2009), most of which are specific to urban areas, but there is a wide gap with regard to crime occurrence at the national level - this being the goal that this paper seeks to achieve. Moreover, in this research, two models of Similarity and COPRAS (Appendix 1) are used to analyze inequalities, which have advantages over other multi-criteria decision-making models used in previous studies and they cover many of their weaknesses. For instance, these two methods are capable of using quantitative and qualitative criteria simultaneously for the 
evaluation of options and they also can calculate the positive and negative criteria separately in the evaluation process.

\section{Methodology}

Iran, with an area of over 1.6 million $\mathrm{km}^{2}$, is located in the southern part of the temperate northern region, between $25^{\circ} 4^{\prime}$ to $39^{\circ} 46^{\prime}$ of northern latitude from the Equator line, and $44^{\circ} 2^{\prime}$ to $63^{\circ} 19^{\prime}$ of eastern longitude from the prime meridian. Its average elevation is over $1200 \mathrm{~m}$ above the sea level. Iran is bounded by the Caspian Sea and by Azerbaijan, Armenia, and Turkmenistan to the north, by Afghanistan and Pakistan to the east, by the Oman Sea and the Persian Gulf to the south, and by Iraq and Turkey to the west. In 2016, Iran had 31 provinces, 429 cities, 1058 districts, 1246 towns, 2589 villages, and a population of 79926270 people.

The research method is descriptive-analytical, and also documentary and library data collection methods are used. The statistical population is divided between 31 provinces of Iran. The indicators consist of 7 main indicators (1. Murder; 2 . Discovered drugs - kg; 3 . Intentional poisoning; 4. Beating, battery, and harm; 5 . Coercion and duress; 6 . Knife threat; 7 . Threat) in the area of crime, which were standardized in proportion to the population of each province in 2016 (Table 1). The Similarity and COPRAS methods are used to investigate and analyze the crime rate and the mean rank method is employed to determine the prioritization strategy. The cluster analysis method is used in the SPSS software for classifying the different regions of the country and the ARC GIS software is used to represent the spatial distribution of crime occurrence. It should be noted that the Shannon Entropy method was used in the present research for weighting the applied indicators.

Indicators examined in the spatial distribution of crime in relation to the

Table 1 population of each province

\begin{tabular}{|c|c|c|c|}
\hline 1. Murder & $\begin{array}{c}\text { 2. Discovered drugs } \\
(\mathrm{kg})\end{array}$ & $\begin{array}{c}\text { 3. Intentional } \\
\text { poisoning }\end{array}$ & $\begin{array}{c}\text { 4. Beating, battery, } \\
\text { and harm }\end{array}$ \\
\hline $\begin{array}{c}\text { 5. Coercion and } \\
\text { duress }\end{array}$ & 6. Knife threat & 7. Threat & \\
\hline
\end{tabular}

Source: authors' calculations (2020)

The COPRAS method (Comprehensive Proportion Assessment method) is one of the compromise methods that were first proposed by Zavadskas et al. (2015a, 2015b). The COPRAS method has relatively provided an optimal solution from the ideal positive and negative solution (Table 2); hence, it can be considered similar to the TOPSIS method (Razavi et al. 2014).

The similarity method solves the problem in the Euclidean geometric space (Table 3 ). In other words, due to the different types of criteria, this technique initially un-scales all of them and it enters them into the Euclidean geometric space. Then, it defines both positive and negative virtual ideal options, which are composed of the best and worst situations, respectively. Afterwards, the distance of each of the options from the positive and negative ideals is measured and an option will be better - the one that has the least distance from the positive ideal and the longest distance from the negative ideal. It has a minor problem, which neglects the position of the points with options and their angles of deviation with an increase in the problem dimension. Hence, Deng (2007) attempted to fix this problem. According to Deng (2007), any option that was previously introduced as a point must be converted into a vector. Therefore, the positive and negative ideals must be a vector. Furthermore, Deng (2007) 
introduced a term known as degree of similarity that is equivalent to the image ratio of its option on the ideal vector. The higher the degree of similarity of an option to the positive ideal, the better situation the option will have.

\section{Steps to perform the method of the chorus}

Table 2

\begin{tabular}{|c|c|c|}
\hline $\begin{array}{l}\text { Step 1: Form the decision } \\
\text { matrix. } \\
X=\left[\begin{array}{cccc}x_{11} & x_{12} & \cdots & x_{1 m} \\
x_{21} & x_{22} & \cdots & x_{2 m} \\
\vdots & \vdots & \vdots & \vdots \\
x_{n 1} & x_{n 2} & \cdots & x_{n m}\end{array}\right]\end{array}$ & $\begin{array}{c}\text { Step 2: Non-Scale Matrix. } \\
\text { For positive or profit indicators }(\mathrm{B}), \text { for } \\
\text { negative or cost indicators }(\mathrm{C}), \\
x_{i f / \max x_{i f}}\end{array}$ & $\begin{array}{l}\text { Step 3: Calculate } \\
\text { the Weightless } \\
\text { Weighting Matrix: } \\
\text { At this stage, the } \\
\text { weight of each } \\
\text { index (W_lj) is } \\
\text { multiplied by an } \\
\text { unbalanced matrix } \\
\text { and the matrix X- } \\
\text { ij is obtained. }\end{array}$ \\
\hline $\begin{array}{l}\text { Step 4: The value of the indi- } \\
\text { ces that are most desirable } \\
\text { (profit indicators) are added } \\
\text { to each of the m options and } \\
\text { it is represented by } \mathrm{P}_{-}(\mathrm{I}), \mathrm{I}= \\
1,2 \ldots \mathrm{m} \text {. } \\
\qquad P_{\mathrm{i}}=\sum_{j \in B} \hat{x}_{i j} \bar{i}=1_{v} 2_{v} \text { ax }\end{array}$ & $\begin{array}{l}\text { Step 5: The minimum values of R_l } \\
\text { are determined based on: } \\
R_{\text {min }}=\min R_{i} \quad i_{i} \tilde{i}=1_{x} 2_{v m s} m\end{array}$ & $\begin{array}{l}\text { Step 6: The de- } \\
\text { gree of utility of } \\
\text { each option is } \\
\text { calculated. } \\
N_{i}=\frac{Q_{i}}{K} \times 100 \%\end{array}$ \\
\hline
\end{tabular}

Source: Razavi et al. (2014)

Procedures for carrying out the similarity method (Source: Deng (2007)

\begin{tabular}{|c|c|c|}
\hline $\begin{array}{l}\text { Step 1: Formation Decision } \\
\text { Matrix: Similar to Other De- } \\
\text { cision Techniques }\end{array}$ & $\begin{array}{l}\text { Step 2: Scalable } \\
\text { decision matrix: } \\
\text { Similar to the TOP- } \\
\text { SIS technique } \\
\text { used by the Euclid- } \\
\text { ean method } \\
\boldsymbol{n}_{i j}=r_{i j} / \sqrt{\sum_{i=1}^{m} r_{i j}^{2}}\end{array}$ & $\begin{array}{l}\text { Step 3: Calculate the Randomized Scalar } \\
\text { Matrix: Obtain the unbalanced matrix in } \\
\text { the weight index of the indices: } \\
\qquad V=N \approx w\end{array}$ \\
\hline $\begin{array}{l}\text { Step 4: Identify the positive } \\
\text { and negative ideal options } \\
A^{+}=\left\{v_{i j} \mid\left(\max _{i} v_{i j}, j \in J\right),\left(\min _{i j}, j \in j\right)\right\} \\
A^{-}=\left\{v_{i j} \mid\left(\min _{i} v_{i j}, j \in J\right),\left(\max _{i} v_{i j}, j \in j\right)\right\}\end{array}$ & $\begin{array}{l}\text { Step 5: Moving the } \\
\text { Problem Space: At } \\
\text { this point, the } \\
\text { origin of the coordi- } \\
\text { nates must be } \\
\text { transferred from (O } \\
\text { and O) to the nega- } \\
\text { tive ideal point, so } \\
\text { it is imperative that } \\
\text { the data of all the } \\
\text { options, positive } \\
\text { and negative ideal } \\
\text { of negative ideal } \\
\text { values, are deduc- } \\
\text { ted. This is an ideal } \\
\text { to zero. }\end{array}$ & $\begin{array}{l}\text { Step 6: Calculates the degree of integer } \\
\text { with positive ideals } \\
\text { Length from origin }=\sqrt{\sum x_{i}^{2}} \quad S^{+}{ }_{i}=\frac{x}{\left|I^{+}\right|}=\frac{\cos \theta\left|A_{i}^{+}\right|}{\left|I^{+}\right|} \\
\qquad \begin{aligned} \cos \theta= & \frac{\sum \sum x_{0} y_{i}}{\sqrt{\sum x_{i}^{2} \sum y_{i}^{2}}} \cos \theta=\frac{x}{\left|A_{i}^{+}\right|} \\
x & =\cos \theta\left|A_{i}^{+}\right|\end{aligned}\end{array}$ \\
\hline
\end{tabular}




\section{Results}

Findings from the Similarity model

The findings of the Similarity model (Table 4) show that the spatial distribution of crime rate is very different in the provinces of Iran. As observed, the three provinces of Fars, Yazd, and

Table 4

Status of different provinces of the country according to their crime rate, based on the similarity model

\begin{tabular}{|c|c|c|c|c|c|}
\hline Province & COS & $\mathbf{A}$ & $\mathbf{S}$ & COS * I A I & RANK \\
\hline East Azerbaijan & 0.79 & 0.01 & 0.03 & 0.010 & 18 \\
\hline West Azerbaijan & 0.70 & 0.02 & 0.05 & 0.017 & 15 \\
\hline Ardabil & 0.67 & 0.08 & 0.16 & 0.053 & 6 \\
\hline Isfahan & 0.62 & 0.01 & 0.02 & 0.008 & 19 \\
\hline Alborz & 0.76 & 0.10 & 0.22 & 0.074 & 5 \\
\hline Ilam & 0.68 & 0.01 & 0.02 & 0.005 & 23 \\
\hline Bushehr & 0.62 & 0.01 & 0.01 & 0.004 & 24 \\
\hline Tehran & 0.88 & 0.04 & 0.09 & 0.031 & 10 \\
\hline Chaharmahal and Bakhtiari & 0.31 & 0.06 & 0.05 & 0.018 & 14 \\
\hline South Khorasan & 0.66 & 0.13 & 0.25 & 0.082 & 4 \\
\hline Khorasan Razavi & 0.63 & 0.01 & 0.02 & 0.007 & 21 \\
\hline North Khorasan & 0.43 & 0.02 & 0.02 & 0.008 & 20 \\
\hline Khuzestan & 0.23 & 0.00 & 0.00 & 0.001 & 31 \\
\hline Zanjan & 0.38 & 0.06 & 0.07 & 0.022 & 12 \\
\hline Semnan & 0.52 & 0.06 & 0.09 & 0.030 & 11 \\
\hline Sistan and Baluchestan & 0.37 & 0.10 & 0.11 & 0.036 & 8 \\
\hline Fars & 0.63 & 0.20 & 0.38 & 0.128 & 1 \\
\hline Qazvin & 0.59 & 0.01 & 0.01 & 0.003 & 25 \\
\hline Qom & 0.65 & 0.05 & 0.10 & 0.032 & 9 \\
\hline Kurdistan & 0.77 & 0.03 & 0.06 & 0.019 & 13 \\
\hline Kerman & 0.41 & 0.04 & 0.04 & 0.015 & 16 \\
\hline Kermanshah & 0.43 & 0.00 & 0.01 & 0.002 & 28 \\
\hline $\begin{array}{l}\text { Kohgiluyeh and Boyer Ah- } \\
\text { mad }\end{array}$ & 0.63 & 0.01 & 0.02 & 0.005 & 22 \\
\hline Golestan & 0.52 & 0.00 & 0.01 & 0.002 & 29 \\
\hline Gilan & 0.54 & 0.00 & 0.00 & 0.001 & 30 \\
\hline Lorestan & 0.54 & 0.00 & 0.01 & 0.002 & 26 \\
\hline Mazandaran & 0.32 & 0.01 & 0.01 & 0.002 & 27 \\
\hline Markazi & 0.64 & 0.02 & 0.04 & 0.014 & 17 \\
\hline Hormozgan & 0.59 & 0.19 & 0.33 & 0.111 & 3 \\
\hline Hamedan & 0.69 & 0.07 & 0.14 & 0.048 & 7 \\
\hline Yazd & 0.66 & 0.19 & 0.37 & 0.123 & 2 \\
\hline
\end{tabular}

Source: authors' calculations (2020)

Hormozgan ranked first to third in terms of studied criteria, with the priority coefficients of $0.128,0.123$, and 0.111 , respectively, while they had the worst conditions (the highest crime rate) among other provinces. In the next steps, there are the provinces such as South Khorasan, Alborz, Ardabil, Hamedan, Sistan and Baluchestan, Qom, and Tehran, with the priority coefficients of $0.082,0.074,0.053,0.048,0.036,0.032$, and 0.031 , and these provinces are in a bad situation in terms of crime occurrence. In contrast, the least amount of crime 
occurrence based on the Similarity model was related to the provinces of Khuzestan, Lorestan, Gilan, Golestan, Kermanshah, Mazandaran, and Qazvin. In order to determine the status of each province, based on their similarity in the survey indicators, the results of the Similarity model are clustered using the SPSS software. In the cluster analysis, various provinces of the country are classified in various clusters based on the nearest neighborhood (Fig. 1).

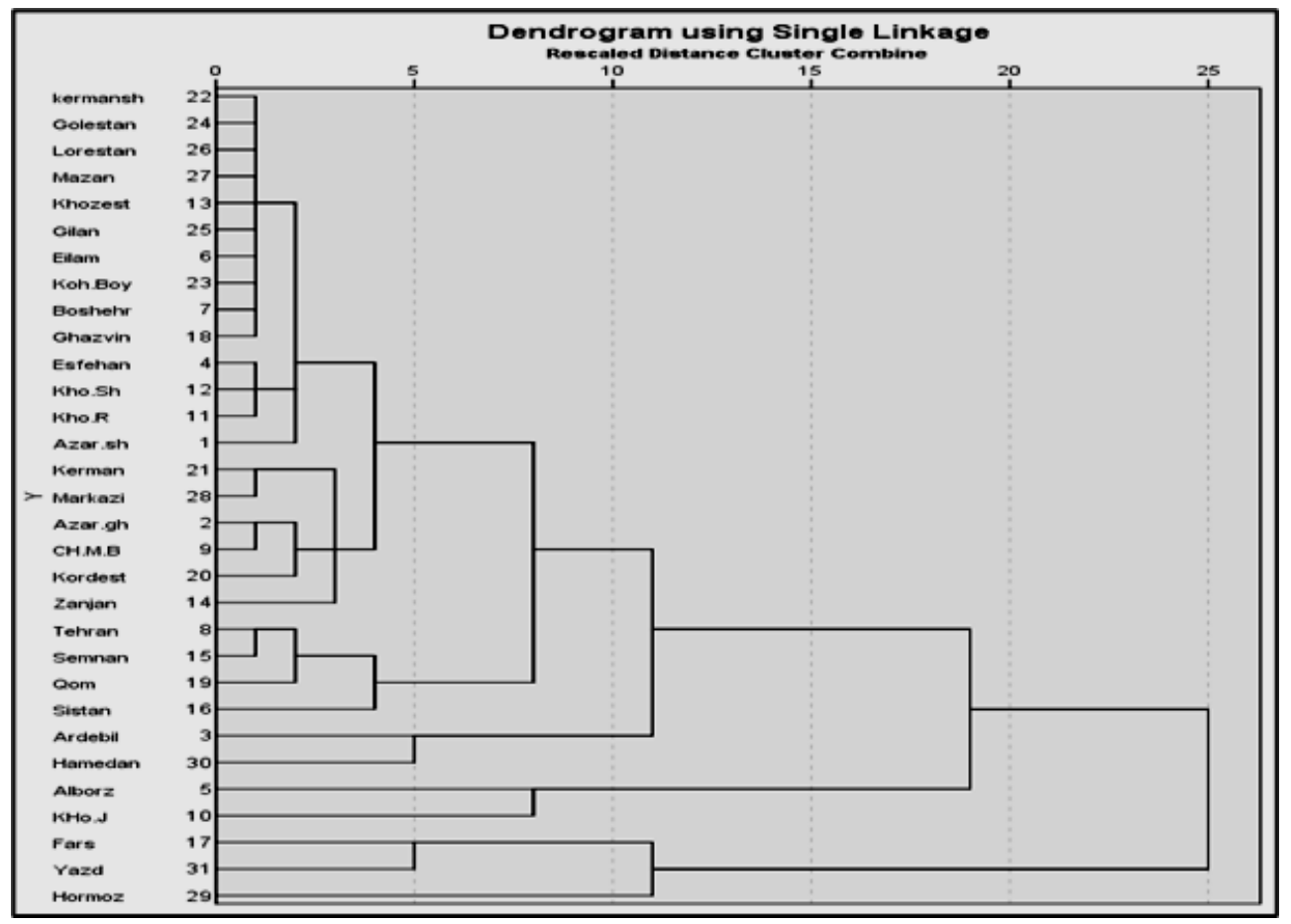

Fig. 1 - Hierarchical clustering of the provinces of the country based on the Similarity Index

Source: authors' calculations (2020)

The results of the hierarchical cluster analysis are shown based on the nearest neighborhood and with regard to the final results of the Similarity model. Accordingly, the provinces of the country are grouped into 6 homogeneous groups, which are obtained based on the similarity of the provinces of the country in terms of crime indicators. It should be noted that, in the performed clustering, the sixth cluster indicates the worst situation and the first cluster indicates the best situation. First cluster: in this cluster, the provinces of Qazvin, Bushehr, Kohgiluyeh and Boyerahmad, Ilam, Gilan, Khuzestan, Mazandaran, Lorestan, Golestan, and Kermanshah were located. In fact, the above-mentioned provinces had the best situation or, in other words, were the safest provinces in terms of crime indicators, with the average final coefficient of 0.003 , compared to other provinces of the country. Second cluster: in this cluster, the four provinces of East Azerbaijan, Khorasan Razavi, North Khorasan, and Isfahan were located with the average final coefficient of 0.008 , which had a slightly better situation than the other provinces of the country, except the provinces located in the first cluster. Third cluster: the results show that provinces of Zanjan, Kurdistan, Chaharmahal and Bakhtiari, West Azerbaijan, Markazi, and Kerman are located with the final coefficient of 0.018. Six of the above provinces have an inappropriate situation than two earlier clusters, but they are in a more appropriate 
situation than the two other provinces located in the next clusters. Fourth cluster: in this cluster, the 4 provinces of Sistan and Baluchestan, Qom, Semnan, and Tehran are located with the final coefficient of 0.032 . These provinces have a worse situation in crime indicators than the earlier clusters and they are in fact among the unsafe provinces. It should be noted that these provinces have a more suitable condition than the provinces located in Clusters 5 and 6 , but they were in an inappropriate situation compared to all groups. Fifth cluster: in this cluster, the four provinces of South Khorasan, Alborz, Hamedan, and Ardabil are located with the final coefficient of 0.064 , which have a relatively more suitable condition than the provinces in the sixth cluster and they have an inappropriate condition compared with other provinces of the country in terms of the examined indicators. Sixth cluster: the results showed that 3 provinces of Fars, Yazd, and Hormozgan, with the final coefficient of 0.120 , were in the worst situation. These three provinces have the highest crime rates for the survey indicators and they are located in the unsafe group of the provinces.

The final results from the cluster analysis based on the Similarity model indicate a wide gap between the provinces of the country in terms of the examined indicators, so that the final coefficient obtained for the provinces in the sixth cluster (the most unsafe group) is about 40 times of the final coefficient of the provinces in the first cluster (the safest provinces in the country).

\section{Spatial representation of the status of crime indicators in the provinces of Iran, based on the} Similarity model

After clustering the provinces of the country in terms of crime indicators based on the similarity model, the results were entered into the GIS software and the spatial distribution of the survey indicators in the provinces of the country was shown (Fig. 2). As it can be seen, the spatial

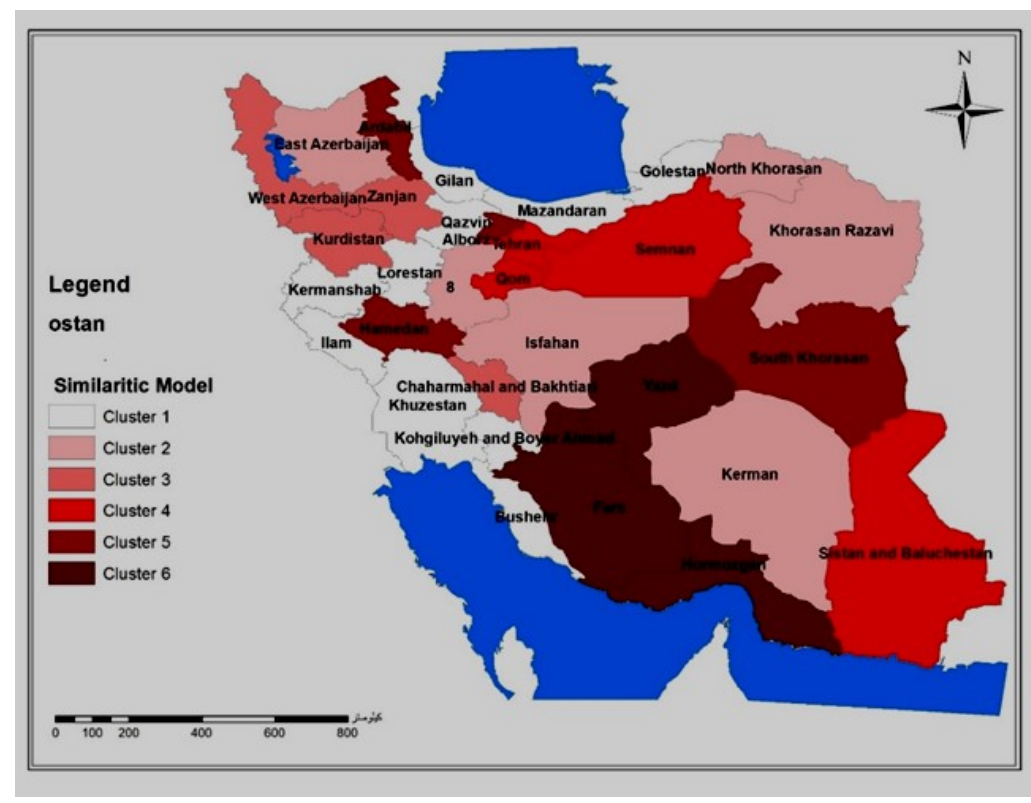

Fig. 2 - Spatial distribution and cluster analysis of crime indicators in the provinces of Iran, based on the Similarity Model Source: authors' calculations (2020) 
Status of different provinces of the country according to their rate of crime, based on the COPRAS model

\begin{tabular}{|c|c|c|c|c|c|c|c|}
\hline Province & PI & $\mathbf{R I}$ & RMIN.RI & 1.RI & $\mathbf{Q}$ & $\mathbf{N}$ & RANK \\
\hline East Azerbaijan & 0.0041 & 0.0003 & 0.0022 & 3673.48 & 0.00 & 4.67 & 20 \\
\hline West Azerbaijan & 0.0078 & 0.0004 & 0.0014 & 2390.64 & 0.01 & 8.76 & 17 \\
\hline Ardabil & 0.0322 & 0.0003 & 0.0023 & 3879.59 & 0.03 & 36.11 & 7 \\
\hline Isfahan & 0.0031 & 0.0001 & 0.0078 & 13346.95 & 0.00 & 3.50 & 21 \\
\hline Alborz & 0.0344 & 0.0004 & 0.0015 & 2598.03 & 0.03 & 38.58 & 6 \\
\hline Ilam & 0.0031 & 0.0000 & 0.1225 & 208694.51 & 0.00 & 3.51 & 22 \\
\hline Bushehr & 0.0017 & 0.0000 & 0.2296 & 391070.52 & 0.00 & 1.96 & 25 \\
\hline Tehran & 0.0117 & 0.0004 & 0.0017 & 2829.23 & 0.01 & 13.12 & 14 \\
\hline $\begin{array}{c}\text { Chaharmahal and } \\
\text { Bakhtiari }\end{array}$ & 0.0150 & 0.0004 & 0.0014 & 2451.37 & 0.02 & 16.84 & 11 \\
\hline South Khorasan & 0.0537 & 0.0001 & 0.0046 & 7835.32 & 0.05 & 60.24 & 4 \\
\hline Khorasan Razavi & 0.0045 & 0.0001 & 0.0095 & 16213.14 & 0.00 & 5.03 & 19 \\
\hline North Khorasan & 0.0047 & 0.0001 & 0.0066 & 11301.41 & 0.00 & 5.29 & 18 \\
\hline Khuzestan & 0.0006 & 0.000 & 1.0000 & 1703288.20 & 0.00 & 0.70 & 31 \\
\hline Zanjan & 0.0193 & 0.0003 & 0.0021 & 3550.32 & 0.02 & 21.64 & 9 \\
\hline Semnan & 0.0126 & 0.0004 & 0.0015 & 2606.89 & 0.01 & 14.17 & 12 \\
\hline $\begin{array}{c}\text { Sistan and } \\
\text { Baluchestan }\end{array}$ & 0.0353 & 0.0003 & 0.0020 & 3460.15 & 0.04 & 39.57 & 5 \\
\hline Fars & 0.0883 & 0.0001 & 0.0074 & 12587.67 & 0.09 & 98.99 & 2 \\
\hline Qazvin & 0.0015 & 0.0003 & 0.0022 & 3775.53 & 0.00 & 1.63 & 26 \\
\hline Qom & 0.0173 & 0.0002 & 0.0036 & 6196.35 & 0.02 & 19.40 & 10 \\
\hline Kurdistan & 0.0105 & 0.0003 & 0.0021 & 3654.79 & 0.01 & 11.74 & 16 \\
\hline Kerman & 0.0118 & 0.0001 & 0.0047 & 8286.26 & 0.01 & 13.19 & 13 \\
\hline Kermanshah & 0.0009 & 0.0000 & 0.4252 & 724314.50 & 0.00 & 1.02 & 29 \\
\hline $\begin{array}{l}\text { Kohgiluyeh and } \\
\text { Boyer Ahmad }\end{array}$ & 0.0027 & 0.0000 & 0.1456 & 247986.90 & 0.00 & 3.08 & 23 \\
\hline Golestan & 0.0010 & 0.0000 & 0.0303 & 51553.45 & 0.00 & 1.09 & 28 \\
\hline Gilan & 0.0007 & 0.0000 & 0.0189 & 32127.92 & 0.00 & 0.79 & 30 \\
\hline Lorestan & 0.0011 & 0.0000 & 0.3852 & 656108.84 & 0.00 & 1.18 & 27 \\
\hline Mazandaran & 0.0023 & 0.0000 & 0.6746 & 1149117.18 & 0.00 & 2.61 & 24 \\
\hline Markazi & 0.0105 & 0.0003 & 0.0023 & 3872.30 & 0.01 & 11.78 & 15 \\
\hline Hormozgan & 0.0777 & 0.0002 & 0.0026 & 4365.82 & 0.08 & 87.09 & 3 \\
\hline Hamedan & 0.0320 & 0.0005 & 0.0012 & 1988.81 & 0.03 & 35.91 & 8 \\
\hline Yazd & 0.0892 & 0.0004 & 0.0015 & 2580.55 & 0.09 & 100.00 & 1 \\
\hline
\end{tabular}

Source: authors' calculations (2020)

distribution of crime indicators was uneven in the country and it did not follow the specific spatial distribution process. However, the results show that the status of crime indicators in the western and northern parts of the country (the provinces adjacent to the Caspian Sea), as well as in the northeastern part of the country, have an acceptable status and the status of the survey indicators in the center and the north (with the exception of the provinces adjacent to the Caspian Sea), northwest, and southeast of the country is inappropriate.

The results of the COPRAS model (Table 5) show that the spatial distribution of crime occurrence in the Iranian provinces is very different, being similar to the results of the Similarity 
model. According to the results of the COPRAS model, the four provinces of Yazd, Fars, Hormozgan, and South Khorasan ranked first to third in terms of indicators, with the importance coefficient of $100,98.99,87.09$, and 60.24 , respectively, which have the worst situation among the provinces of the country. In the next ranks, the provinces such as Sistan and Baluchestan, Alborz, Hamedan, and Ardabil are located and these provinces have been in inappropriate conditions for crime occurrence compared to other provinces. In contrast, the lowest crime rate occurred, based on the COPRAS model, in provinces such as Khuzestan, Gilan, Kermanshah, Golestan, Lorestan, Qazvin, Bushehr, Mazandaran, Kohgiluyeh and Boyer Ahmad, Isfahan, and llam. In order to determine the status of each province based on their similarity in the surveyed indicators, the results of the COPRAS model were clustered using the SPSS software. In the cluster analysis, different provinces of the country were classified in various clusters based on the nearest neighborhood (Fig. 3).

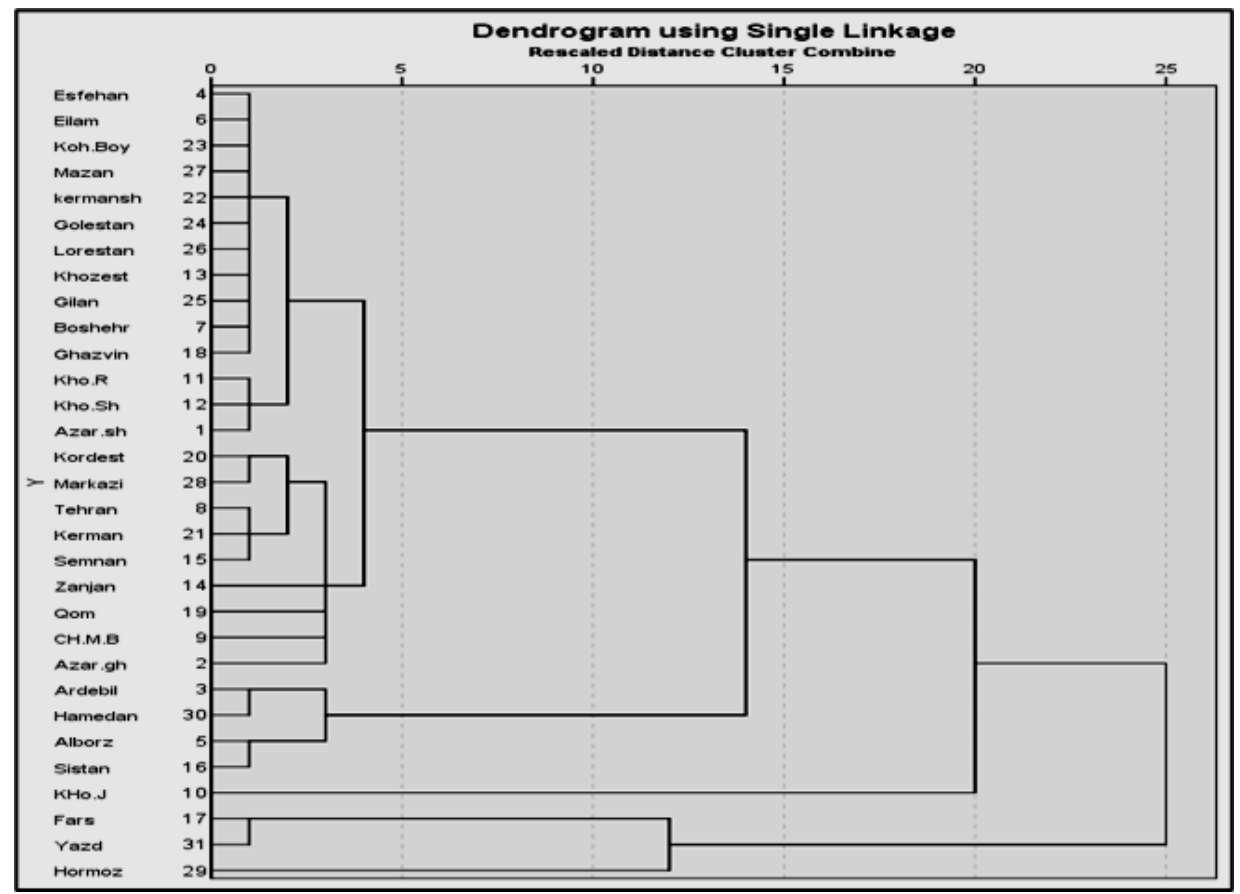

Fig. 3-The hierarchical clustering of the provinces of the country based on the COPRAS Index

Source: authors' calculations (2020)

In the cluster analysis using the COPRAS method, the same as the similarity model, the provinces of the country are classified into 6 homogeneous groups and these groups are obtained based on the similarity of the provinces of the country in terms of the surveyed indicators. It should be noted that in the clustering that has been made, the sixth cluster indicates the worst condition and the first cluster indicates the best condition. First cluster: in this cluster, the provinces of Qazvin, Bushehr, Gilan, Khuzestan, Isfahan, Ilam, Lorestan, Golestan, Kermanshah, Kohgiluyeh and Boyerahmad, and Mazandaran are located. In fact, the above-mentioned provinces were in the best situation with the average coefficient of 1.92 compared to other provinces of the country in terms of crime indicators, or, in other words, they 
were the safest provinces of the country. Second cluster: in this cluster, there were three provinces of East Azerbaijan, North Khorasan, and Khorasan Razavi with the importance coefficient of 4.99 , which have a slightly more appropriate situation than the other provinces of the country, except the provinces in the first cluster.

Third cluster: the results showed that the provinces of Semnan, Kerman, Tehran, Markazi, and Kurdistan, with the importance coefficient of 12.80, were in this cluster. The five aforementioned provinces have inappropriate situation compared to two previous clusters, but compared to the other provinces located in the next clusters, they were in a better situation. Fourth cluster: in this cluster, there were 4 provinces of West Azerbaijan, Chaharmahal and Bakhtiari, Qom, and Zanjan, with the importance coefficient of 16.66. These provinces have a worse situation than the previous clusters for crime indicators; in fact, they are located in the group of the unsafe provinces of the country. It should be noted that these provinces have a better situation than the provinces located in clusters 5 and 6 , but they were in an inappropriate situation compared to all other groups. Fifth cluster: in this cluster, there are the four provinces of Sistan and Baluchestan, Alborz, Hamedan, and Ardabil, with the importance coefficient of 37.54 , which have a more appropriate situation than the provinces in the sixth cluster and they have an inappropriate situation compared to the other provinces for the survey indicators. Sixth cluster: the results show that the 4 provinces of Fars, Yazd, Hormozgan, and South Khorasan are in the worst condition with the importance coefficient of 86.58. These three provinces had the highest crime rates in terms of survey indicators and they were in the most unsafe group of provinces.

The final results from the cluster analysis based on the COPRAS model, the same as the Similarity model, indicate a deep gap between the provinces of Iran in terms of the survey indicators, so that the final coefficient obtained for the provinces located in the sixth cluster (the most unsafe group) is about 45 times of the final coefficient of the provinces located in the first cluster (the safest group).

\section{Spatial representation of crime indicators in the provinces of Iran based on the COPRAS model}

After clustering the provinces of the country in terms of the indicators based on the COPRAS model, the results were entered into the GIS software and the spatial distribution of the surveyed indicators in the provinces of the country was shown (Fig. 4). As it can be seen, the spatial distribution of the indicators in the country, based on COPRAS model, was uneven and it did not follow a specific spatial distribution process. Nevertheless, it can be said that the status of crime indicators in the western, southwestern, northern, as well as northeastern parts of the country, is acceptable and the status of the surveyed indicators in the central, northwestern, and southeastern parts of the country is unsuitable.

\section{Determining the prioritization strategy using the mean rank method}

Given the little difference in the results of the spatial analysis of crime occurrence in the provinces of Iran, based on the two models of Similarity and COPRAS, the mean rank method is used to eliminate these differences and to determine the real status of each province, as well as to determine the prioritization strategy.

Based on the final results obtained from the mean rank method (Table 6), the provinces of Yazd, Fars, Hormozgan, and South Khorasan, with the final importance coefficients of 50.06, 49.56, 43.60, and 30.16, ranked first to fourth and they had the worst situation among the provinces of the country. In the next ranks, the provinces Sistan and Baluchestan, Alborz, 
Determine the prioritization strategy based on the rank average method

\begin{tabular}{|c|c|c|c|c|c|}
\hline Province & $\begin{array}{c}\text { Mean } \\
\text { Rank }\end{array}$ & $\begin{array}{c}\text { Final } \\
\text { rank }\end{array}$ & Ostan & $\begin{array}{c}\text { Mean } \\
\text { Rank }\end{array}$ & Final rank \\
\hline Yazd & 1.5 & 1 & Markazi & 16 & 17 \\
\hline Fars & 1.5 & 2 & East Azerbaijan & 19 & 18 \\
\hline Hormozgan & 3 & 3 & North Khorasan & 19 & 19 \\
\hline South Khorasan & 4 & 4 & Khorasan Razavi & 20 & 20 \\
\hline Alborz & 5.5 & 5 & Isfahan & 20.5 & 21 \\
\hline Ardabil & 5.6 & 6 & llam & 22 & 22 \\
\hline $\begin{array}{c}\text { Sistan and Ba- } \\
\text { luchestan }\end{array}$ & 6.5 & 7 & $\begin{array}{c}\text { Kohgiluyeh and } \\
\text { Boyerahmad }\end{array}$ & 22.5 & 23 \\
\hline Hamedan & 7.5 & 8 & Bushehr & 24.5 & 24 \\
\hline Qom & 9.5 & 9 & Qazvin & 25.5 & 25 \\
\hline Zanjan & 10.5 & 10 & Mazandaran & 25.5 & 26 \\
\hline Semnan & 11.5 & 11 & Lorestan & 26.5 & 27 \\
\hline Tehran & 12 & 12 & Kermanshah & 28.5 & 28 \\
\hline $\begin{array}{c}\text { Chaharmahal } \\
\text { and Bakhtiari }\end{array}$ & 12.5 & 13 & Golestan & 28.5 & 29 \\
\hline Kurdistan & 14.5 & 14 & Gilan & 30 & 30 \\
\hline Kerman & 14.5 & 15 & Khuzestan & 31 & 31 \\
\hline West Azerbaijan & 16 & 16 & & & \\
\hline \hline
\end{tabular}

Source: authors' calculations (2020)

Hamedan, and Ardabil are located, and these provinces have been in an inappropriate condition for crime occurrence compared to other provinces. In contrast, the lowest crime rate occurred, based on mean rank method, in the provinces such as Isfahan, Ilam, Kohgiluyeh and Boyerahmad, Mazandaran, Kermanshah, Golestan, Lorestan, Khuzestan, Gilan, Bushehr, and Qazvin. Finally, the cluster analysis obtained from the results of the mean rank method is investigated (Fig. 5).

In the final clustering, based on the mean rank method, the provinces of the country are located in 6 homogeneous clusters. In this clustering, the sixth cluster indicates the worst condition and the first cluster indicates the best condition. First cluster: in this cluster, the provinces of Isfahan, Ilam, Kohgiluyeh and Boyerahmad, Mazandaran, Kermanshah, Golestan, Lorestan, Khuzestan, Gilan, Bushehr, and Qazvin are located. In fact, the above provinces, with the final importance coefficient of 0.96 , were in the best situation for the crime occurrence indicators, or, in other words, they are the safest provinces of the country. Second cluster: in this cluster, three provinces of Khorasan Razavi, North Khorasan, and East Azerbaijan, with the average importance coefficient of 2.50 , are located, which have a slightly more appropriate situation than the other provinces in the country, except the provinces in the first cluster.

Third cluster: the results showed that the provinces of Kurdistan, Markazi, Tehran, Kerman, and Semnan, with the importance coefficient of 6.41 , are located in this cluster. The five aforementioned provinces have an inappropriate situation compared to the two previous 


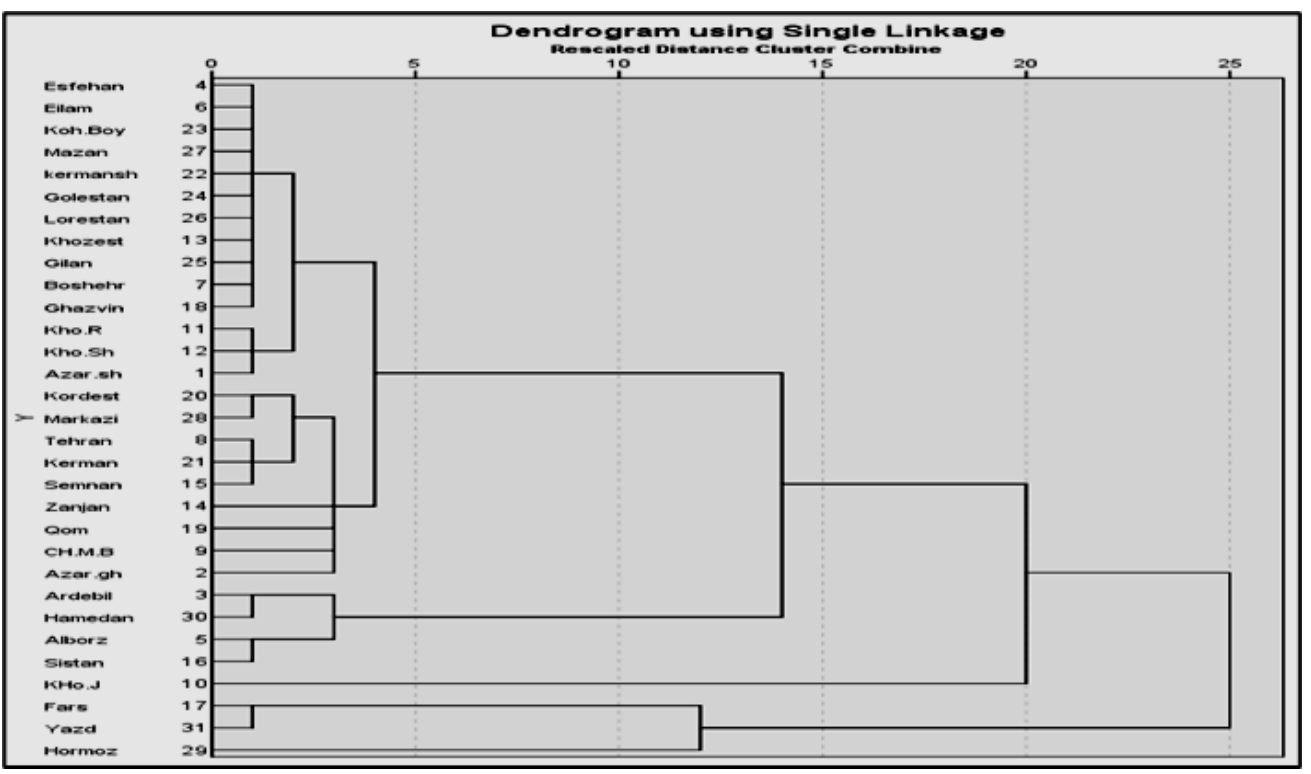

Fig. 5-Final clustering of the provinces of the country based on the average ratings method

Source: authors' calculations (2020)

clusters, but, compared to the other provinces located in the next clusters, they are in a better situation. Fourth cluster: in this cluster, there were the 4 provinces of Zanjan, Qom, West Azerbaijan, and Chaharmahal and Bakhtiari, with the importance coefficient of 7.83 . These provinces had a worse situation than the previous clusters for crime indicators; in fact, they were located in the group of the unsafe provinces of the country. Fifth cluster: in this cluster, there are the four provinces of Ardabil, Hamedan, Alborz, and Sistan and Baluchestan, with the importance coefficient of 18.80 , which have a slightly more appropriate situation than the provinces in the sixth cluster and they have an inappropriate situation compared to the other provinces for the surveyed indicators. Sixth cluster: the results show that the 4 provinces of Fars, Yazd, Hormozgan, and South Khorasan are in the worst condition with the importance coefficient of 43.35. These four provinces have the highest crime rate in terms of the examined indicators and they are in the most unsafe group of provinces. The final results of the cluster analysis based on mean rank method indicate a wide gap between the provinces of the country in terms of the survey indicators, so that the final coefficient obtained for the provinces in the sixth cluster (the most unsafe group) is about 45 times of the final coefficient of the provinces in the first cluster (the safest group).

\section{Spatial representation of the status of crime indicators in the provinces of Iran based on the} mean rank method

After the final clustering of the provinces of the country based on the crime rate, with the help of the mean rank method, their spatial distribution is represented using the ARC GIS software (Fig. 6). As it can be found, the final spatial distribution of crime indicators in the different regions of the country did not follow a balanced pattern and it did not have a particular spatial distribution process. However, the spatial distribution of the surveyed indicators in the provinces of Iran can be stated in the following manner: the western, southwestern, northern 


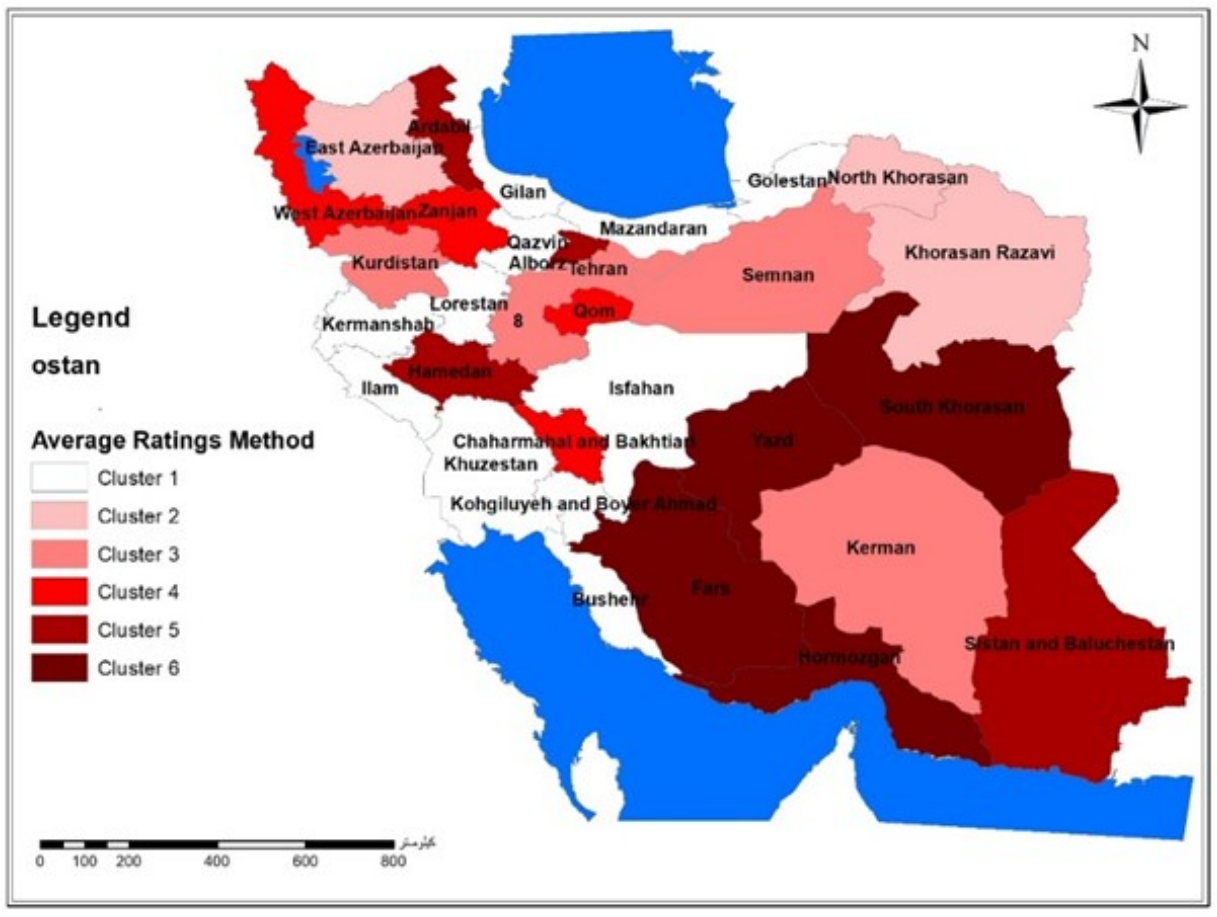

Fig. 6 - The ultimate spatial distribution of crime indicators in the provinces of the country, based on the Average Ratings Method

Source: authors' calculations (2020)

(the provinces adjacent to the Caspian Sea), as well as northeastern parts of the country, have a more acceptable situation than the other parts of the country and the status of the survey indicators in the central, southern, southeastern, northern (excluding the provinces adjacent to the Caspian Sea), and the northwestern provinces is of a very poor situation.

\section{Discussion}

One of the important necessities of this research has been to know the principles and concepts of security, crime prevention approaches, identification of crime hotspots and the extent and types of crime distribution in the provinces of Iran. Therefore, in this study, the provinces of the country were well studied and ranked in terms of crime. The 7 crime indicators in the provinces showed well the distribution of crime in the country. The results obtained from the distribution of crime in the provinces of the country indicated that the provinces located in the central plateau of Iran, the south and the southeast of the country were in a more unfavorable situation than other parts of the country, due to high migration, illiteracy, unemployment, and other conditions. Therefore, they need to provide appropriate security programs, and the attention of officials and of the relevant institutions to deal with crime. In fact, one of the reasons for committing more crime in provinces such as Fars, Yazd and Sistan and Baluchestan, which are in a very insecure situation, could be due to the very large migration from the cities and the neighboring provinces, especially to the center of these provinces. The existence of facilities and suitable 
conditions for the welfare and comfort of people, including the existence of factories and large industrial companies in the centers of Fars and Yazd provinces, has caused many immigrants to these two centers to constitute an illiterate workforce or at the elementary literacy level. This migrant workforce cannot be properly absorbed in these areas due to cultural differences and socialization issues, and many of them have failed to achieve their working goals and the decent income and comfort they expected. And, consequently, they try to provide for themselves in other ways while they provide the ground for insecurity.

Sistan and Baluchestan province, because of its isolated and infertile nature, especially in the desert and arid regions of Iran, has been a source of political, economic and security problems for the current governments due to the lack of welfare and the lack of motivation to live. The potential inability to produce, the lack of employment, the low income and the lack of access to the basic needs have been the main socio-economic characteristics of this region, which has provided the ground for problems and disorders such as migration, smuggling, riots and insecurity. The special geographical situation of this province and some other socio-political conditions indicate the existence of a deep gap between these regions and other regions of the country. The combination of these factors has caused the economy of Sistan and Baluchestan province to be directly and indirectly dependent on illegal border exchanges and it has provided the ground for insecurity in this province. In fact, the results show an overview of the situation of crime in the different provinces of Iran, which has been determined based on the population density of each province, the incidence and the crime rate in there.

\section{Conclusions}

One of the most complex issues in all countries is crime. The occurrence of various types of crimes causes insecurity and it imposes various material and immaterial problems for the society. Given the importance of the discussions related to crimes in welfare, comfort, and the safety of citizens, the comprehensive knowledge of crimes at large scales is one of the necessities that should be considered by the researchers and planners in the country. Evidence shows that there is a severe study gap in this regard and most of the crime-related studies focus on a limited geographical scope while most are specific to urban areas. This has led us to investigate the spatial distribution of crimes at national and large-scale levels given the objective of the paper which is the spatial analysis of crime occurrence in the different provinces of Iran with an emphasis on safety. In so doing, it would be possible to identify the safest and the most unsafe provinces based on the frequency of crime occurrence in each of the provinces, and given the characteristics and features of each province, a planning is done for providing their safety.

In total, the results of the study showed a gap and inequality between the provinces of the country in terms of surveyed indicators, to the extent that the final coefficient obtained for the provinces in the sixth cluster (the most unsafe group) is about 45 times of the final coefficient of the provinces in the first cluster (the safest group). According to the findings of the research, the safest provinces of the country, based on the frequency of crime occurrence in the cluster analysis, were Isfahan, Ilam, Kohgiluyeh and Boyerahmad, Mazandaran, Kermanshah, Golestan, Lorestan, Khuzestan, Gilan, Bushehr, and Qazvin, which had the lowest crime occurrence with the final mean importance coefficient of 0.96 compared to the other provinces of the country. The most unsafe provinces of the country, in terms of the frequency of crime occurrence in seven survey criteria, were Fars, Yazd, Hormozgan, and South Khorasan, which were in the worst situation compared to other provinces, with the final importance coefficient of 43.35. The final results of the spatial distribution of crime indicators also showed that different regions of the country did not follow a balanced pattern and they did not have a particular spatial distribution process. However, the spatial distribution of the surveyed indicators in the provinces of Iran can be stated in a way that the western, southwestern, northern (the 
provinces adjacent to the Caspian Sea), as well as the northeastern parts of the country, had an acceptable situation compared to other parts of the country and they were in fact the most safe areas of the country. Moreover, the status of the surveyed indicators in the central, southern, southeastern, northern (excluding the provinces adjacent to the Caspian Sea), and northwestern provinces were in a very poor situation and, in fact, they are considered as the most unsafe areas of the country.

According to the obtained results, it can be stated that, by legalizing the principles, strategies and executive methods, as well as involving the society in crime prevention, the formation and development of non-governmental organizations in the field of social harms, creating an integrated, participatory and accountable management and, finally, a fair spatial distribution of income, wealth and power in all provinces of the country, can greatly help preventing crime and ensuring social security.

\section{References}

AHMADI H., MOHAMMAD-TAGHI I. (2004,( The Culture of Poverty, Marginalization and the Tendency to Delinquent Behavior among the Marginalized Youth of Dehpialeh in Shiraz, Research Journal of the University of Isfahan 19 (2), 99-118.

ANSELIN L. (2000), GIS, spatial econometrics and social science research, Journal of Geographical Systems 2 (1), 11-15.

ACHU A. L., SUJA ROSE R. S. (2016), GIS Analysis of Crime Incidence and Spatial Variation in Thiruvananthapuram City, International Journal of Remote Sensing Applications 6, 1-7.

ARDIAN N., BAGHIANIMOGHADAM M. H., HEKMATNIA H., EHRAMPOUSH M. H., ARDIAN M., MASOUDNIA E. (2014), The Spatial Analysis of Hot Spots in Urban Areas of Iran. The case Study: Yazd, Revista de Cercetare și Intervenție Socială 44, 103-115.

CARMONA M., TIESDELL S., HEATH T., OC T. (2003), Public Places, Urban Spaces: The dimensions of urban design, Architectural Press, Oxford.

COOK P. J., MACHIN S., MARIE O., MASTROBUONI G. (2013), Crime economics in its fifth decade, in: Cook P. J., Machin S., Marie O., Mastrobuoni G. (eds.), Lessons from the economics of crime: what reduces offending?, The MIT Press, Cambridge, MA, pp. 1-16.

COZENS P. (2008), Crime prevention through environmental design in Western Australia: planning for sustainable urban futures, International Journal of Sustainable Development and Planning 3 (3), 272-292.

COZENS P. M. (2002), Sustainable Urban Development and Crime Prevention through Environmental Design for the British City. Towards an Effective Urban Environmentalism for the 21st Century, Cities 19 (2), 129-137.

CREȚAN R. (2020), Ethnic spatial segregation in European cities: edited by Hans Skifter Andersen, London/New York, Routledge, 2019, 226 pp., £115.00 (hbk), ISBN-978-1-138 -35891-1, Housing Studies 35 (1), 189-191.

CRETTAN R., O'BRIEN T. (2019), 'Get out of Traian Square!': Roma stigmatization as a Mobilizing Tool for the Far Right in Timişoara, Romania, International Journal of Urban and Regional Research 43 (5), 833-847.

DENG H. (2007), A Similarity-Based Approach to Ranking Multicriteria Alternatives, in: Huang D. S., Heutte L., Loog M. (eds.), Advanced Intelligent Computing Theories and Applications. With Aspects of Artificial Intelligence. ICIC 2007. Lecture Notes in Computer Science 4682, Springer, Berlin, Heidelberg, pp. 253-262.

FROMM E. (1981), The sane society, Behjat Publications, Tehran.

GLUECK S., GLUECK E. T. (1950), Unraveling juvenile delinquency, Harvard University Press, Cambridge, MA.

HAJI Y., MOHAMMAD A., BAQIRI A. (2011), Study status of developing the document of I.R of Iran's National Security Strategy, Political Knowledge 7 (2), 69-97. HESHMATI M. (2006), The role of urban planning in crime control, Soffeh 15 (41), 82- 
89.

HOSSEINIUN S. (2007), Providing a sense of safety in the urban space, Journal of Shahrdariha 8 (82), 87-90.

HUNTINGTON E. (1945), Mainsprings of civilization, Wiley, New York.

JAFARI K., MESGARZADEH S., MIRZAKHANI M. (2018), Influential factors on Social Security among citizens of Tabriz, Journal of Sociology Studies 10 (38), 61-83.

JAHANGIRI J., MOSAVAT E. (2013), An Evaluation of the Factors Affecting Woman's Social Security (Case Study: Women Living in Shiraz City), Journal of Strategic Studies on Security and Social Order 6 (2), 41-55.

KALANTARI M., HENDIANI A., SARMAD M. R. (2010), Role of crime hotspots in forming spatial patterns of misdemeanor studied by Aliabad Inspection Station in Birjand (geographical analysis of crime), Police Management Research 5 (4), 563-584.

KAMYAR Q. (2000), Urban Design Rights, Amjad Publications, Tehran.

KAY NIA M. (1994), Fundamentals of Criminology, University of Tehran Press, Tehran.

KREVERS B., MILBERG A. (2014), The instrument 'Sense of Security in Care Patients' Evaluation': its development and presentation, Psycho-Oncology 23 (8), 914-920.

LINDSTRÖM M. (2008), Social capital, anticipated ethnic discrimination and selfreported psychological health: a population-based study, Social Science \& Medicine 66 (1), 1 13.

LUDWIG J., DUNCAN G. J., HIRSCHFIELD P. (2001), Urban Poverty and Juvenile Crime: Evidence from a Randomized Housing-Mobility Experiment, The Quarterly Journal of Economics 116 (2), 655-679.

MALLER J. B. (1937), Juvenile Delinquency in New York City: A Summary of a Comprehensive Report, The Journal of Psychology 3 (1), 1-25

MÁLOVICS G., CRETAN R., MÉREINÉ-BERKI B., TÓTH J. (2019a), Socioenvironmental justice, participatory development, and empowerment of segregated urban Roma: Lessons from Szeged, Hungary, Cities 91, 137-145.

MÁLOVICS G., CREṬAN R., MÉREINÉ BERKI B., TÓTH J. (2019b), Urban Roma, segregation and place attachment in Szeged, Hungary, Area 51 (1), 72-83.

MÉREINE-BERKI, MÁLOVICS G., TÓTH J., CRETTAN R. (2017), The role of social capital and interpersonal relations in the alleviation of extreme poverty and spatial segregation of Romani people in Szeged, Journal of Urban and Regional Analysis 9 (1), 33-50.

MILBERG A., FRIEDRICHSEN M., JAKOBSSON M., NILSSON E.-C., NISKALA B.,

OLSSON M., WÅHLBERG R., KREVERS B. (2014), Patients' Sense of Security During Palliative Care-What Are the Influencing Factors?, Journal of Pain and Symptom Management 48 (1), 45-55

NASIRI E., GOLMEHR E., RAHMANI M. H. (2015), Geo-spatial analysis of crime and crime-prone areas. Case study: Misdemeanor Theft in Qazvin, Geography 12 (43), 157-176.

NAVIDNIA M. (2009), The Police Perspective: Security and Social Capital, Strategic Studies Quarterly 12 (44), 29-46.

NEWTON A. (2015), Crime and the NTE: multi-classification crime (MCC) hot spots in time and space, Crime Science 4, 30.

RAHNEMAEI M. T., POURMOUSAVI S. M. (2006), Investigating security instabilities in Tehran Metropolitan based on urban sustainable development indexes, Geographical Research Quarterly 38 (57), 177-193.

RAZAVI H., HASHEMI S. S., AMOUZADEH M., RAJI H. (2014), Multi-indicator decisionmaking in certainty and uncertainty conditions, Termeh Publications, 196-199.

REZAEI M., BARTAV I., RAJAEE S. A. (2009), Spatial analysis and crime prevention using Geographic Information Systems, Journal of Crime Prevention Studies 4 (11), 129-148.

REZAEI RAD M., DOAGUYAN D., AMIRI R. (2007), Effectiveness of social safety promotion plan for young women's clothing in city of Sari, Journal of Police Management Studies 2 (4), 501-516.

SARAEE M. H., HOSSEINI S. M. (2015), Spatial analysis of crime in city of Yazd, Police Geographical Studies 3 (9), 93-120. 
SAROUKHANI B., HASHEMNEJAD F. (2011), A survey of relationship between social capital, its components, and sense of social safety among youth in city of Sari, Journal of Sociology of Youth Studies 2 (2), 81-94. Tehran.

SHAKOUEI H. (1985), Social Geography of Cities (Social Ecology of the City), ISBA,

SHAW C. R., MCKAY H. D. (2014), Juvenile delinquency and urban areas, in: Anderson T. L. (ed.), Understanding deviance: connecting classical and contemporary perspectives, Routledge, New York, pp. 106-127.

TABRIZI L. R., MADANIPOUR A. (2006), Crime and the City: Domestic Burglary and the Built Environment in Tehran, Habitat International 30 (4), 932-944.

VESALON L., CREȚAN R. (2019), "Little Vienna" or "European avant-garde city"? Branding narratives in a Romanian City, Journal of Urban and Regional Analysis 11 (1), 19-34. WOLFGANG M. E. (1958), Patterns in criminal homicide, University of Pennsylvania Press, Philadelphia.

YAR P., NASIR J. (2016), GIS Based Spatial and Temporal Analysis of Crimes, a Case Study of Mardan City, Pakistan, International Journal of Geosciences 7 (3), 325-334.

ZANGI ABADI A., RAHIMI NADER H. (2010), Spatial analysis of crime in city of Karaj (using GIS), Quarterly of Law 40 (2), 179-198.

ZAVADSKAS E. K., ANTUCHEVIČIENĖ J., KAPLIŃSKI O. (2015a), Multi-criteria decision making in civil engineering: Part I - a state-of-the-art survey, Engineering Structures and Technologies 7 (3), 103-113.

ZAVADSKAS E. K., ANTUCHEVIČIENĖ J., KAPLIŃSKI O. (2015b), Multi-criteria decision making in civil engineering. Part II - applications, Engineering Structures and Technologies 7 (4), 151-167.

ZHONG H., YIN J., WU J., YAO S., WANG Z., LV Z., YU B. (2011), Spatial Analysis for Crime Pattern of Metropolis in Transition Using Police Records and GIS: a Case Study of Shanghai, China, International Journal of Digital Content Technology and its Applications 5, 93105.

\begin{tabular}{|c|c|}
\hline $\begin{array}{l}\text { Abbreviation } \\
\text { signs }\end{array}$ & Equivalent to English \\
\hline ARC GIS & Geographic Information System \\
\hline COPRAS & Complex Proportional Assessment \\
\hline SPSS & Statistical Package for the Social Sciences \\
\hline Cos & Degree of conformity \\
\hline a & Ideally positive \\
\hline $\mathrm{s}$ & The degree of similarity of options vectors \\
\hline $\mathrm{PI}$ & $\begin{array}{l}\text { The sum of the values of the criteria that the } \\
\text { larger values are more preferred }\end{array}$ \\
\hline $\mathrm{RI}$ & $\begin{array}{l}\text { The sum of the values of the criteria that the } \\
\text { smallest values are preferred }\end{array}$ \\
\hline RMIN & Calculate the minimum values of $\mathrm{RI}$ \\
\hline Q & Calculate the relative weight of each option \\
\hline $\mathrm{N}$ & $\begin{array}{l}\text { Calculate the degree of utility of the options } \\
\text { (maximum weight) }\end{array}$ \\
\hline
\end{tabular}

Appendix 1

Abbreviations used in the text and the equivalent to each

Initial submission: 21.09.2019

Revised submission: 29.11 .2020

Final acceptance: 22.12 .2020

Correspondence: Department of Geography and Urban Planning, University of Sistan and Baluchestan, University Boulevard, 98167-45845, Zahedan, Iran.

Email: z.hadyani@gep.usb.ac.ir 
